\title{
Challenges of Medical Records Interoperability in Developing Countries: A Case Study of the University Teaching Hospital in Zambia
}

\author{
Danny Leza ${ }^{1}$, Jackson Phiri ${ }^{2}$ \\ Computer Science Dapartment \\ University of Zambia Lusaka \\ Lusaka, Zambia
}

\begin{abstract}
The University Teaching Hospital (UTH) is an integral national referral Hospital made up of eight departments. Standardized systems and semantic interoperability is key for successful flow of patient information from one department to another and from section to section within a department. Lack of a SNOMED CT E.H.R System in surgery departments causes inefficient scheduling of surgical procedures, insufficient and inaccurate pertinent patient historical information, misconceptions and error arising from ambiguities in terminology usage. The result is unhealthy clinician working environment leading to high death rates among patients. Baseline Survey was conducted using questionnaire to establish the major drawbacks of the current manual system in use at the department. Record inspection was done followed by roundtable discussion with stakeholder. Convenient sampling was used, out of 40 respondents $\mathbf{7 2 . 5 \%}$ had computers in their section, $\mathbf{2 7 . 5 \%}$ did not have, $60 \%$ were using partial electronic records and paper based, $37.5 \%$ were using manual system, $2.5 \%$ reported that they were using electronic record system. The result reviewed more than $50 \%$ of the medical practitioner ranging from nurses to surgeon reported to be dissatisfied with the current system. In addition, record inspection was conducted by going to each section of the department to understand the business process and the form and format of data storage; this exercise reviewed redundancy in the capture, storage and management of patient records due to the fact that in every section where a patient pass, while undergoing diagnosis procedure, basic details are collected afresh for the same patient. This situation has brought about unnecessary duplication of work. The other drawback is the storage of patient records arising from lack of storage space. Record which are ten years old are destroyed to create space for new ones. This destruction of records robs researchers of the much-needed data for trends analysis and patient disease history. Because of these draw backs, it is very apparent that a standardized E.H.R is implemented.
\end{abstract}

Keywords—HER; surgery; ICT; paper based; adoption

\section{INTRODUCTION}

As time goes by, medical care is getting more multifaceted and as new technologies are discovered, there is a need for the medical team to come up with better structures of maintaining the patients' information. Proper and accurate documentation comes in hand in hand with better medical care and implementation policies. The electronic medical record (EMR) is one of the medical tools that seek to improve medical care by providing hospitals with the kind of platform that allows for new services and new functionality. The patient information can then be updated as the patient undergoes new treatment and newer health information is discovered.

According to NIH NCRR [1], the Electronic Health Record (EHR) is a compiled report of all of a patient's health information that includes the patient's demographics, progress notes, problems, medications, vital signs, past medical history, immunizations, laboratory data, and radiology reports. The EHR computerizes this information in an organized manner in which the patient has acquired health care. This is a very important tool in the provision of evidence-based care of a patient and it incorporates different health care departments to ensure an effective and comprehensive health record.

The patients' information also requires to be secure and available in the computerized file for future references. All the medical personnel must be able to assess and understand the information in the patient's file to ensure that the patient undergoes proper treatment and to lessen the workload of having to ask the patient for his basic health information each time he visits the hospital.

A computerized medical record brings with it many advantages [2]. It presents data in a very organized manner so that each hospital department finds the required information without difficulties. This changes the way health care is practiced in that it is very unlikely to overlook important findings.

The success implementation of Electronic Health Records provides another challenge when it comes to common definition of medical terms in which one term can mean different things to different people. The solution is applying a standard in the storage and retrieval of medical records. SNOMED CT is an international standard that can be implemented together with an E.H.R.

According to a report by the European Union [3],the primary purpose of SNOMED CT is to code the meanings that are used in health care delivery and support the clinical recording of health information. SNOMED CT contributes to the improvement of patient care by underpinning the development of Electronic Health Records that record clinical information in ways that enable meaning-based retrieval. This 
provides effective access to information required for clinical decision support and consistent.

\section{A. Overview of Study}

In this study, we seek to understand the challenges faced by the University Teaching Hospital in Lusaka Zambia, Surgery Department, and view of the information system they are using to manage patient records. The study highlights, the importance of electronic health records in. We further propose a clinic terminology standard as a means of alleviating terminology semantic challenges.

\section{B. Importance of Clinical Terminology}

Clinical terminologies[4] are highlighted in the scientific literature as a key factor for improving communication of clinical data and increase availability of relevant information for the various stakeholders within the health sector.

Clinical terminologies have potential to support development and configuration of Electronic Health Records or Clinical Information Systems (CISs) that enable semantic interoperability and support efficient and effective data entry and retrieval [4]. Various definitions of Semantic interoperability in health exist.

"Semantic interoperability means ensuring that the precise meaning of exchanged information is understandable by any other system or application not initially developed for this purpose [5]."

Hence a prerequisite in achieving Semantic interoperability is standardized concept systems (like SNOMED CT) because they are the mean to representing clinical meaning unambiguously. E.H.R are configured to transform the clinicians' documentation needs and requirements for functionality into templates which best support the clinical practice.

\section{Why Focus on Electronic Health Records and Interoperability?}

The World Health Organization (WHO) defined health in its broader sense in its 1948 constitution as "a state of complete physical, mental, and social well-being and not merely the absence of disease or infirmity." [5] This term has been defined elsewhere as "Health is the level of functional and metabolic efficiency of a living organism. In humans [6] it is the ability of individuals or communities to adapt and self-manage when facing physical, mental, psychological and social changes with environment." Healthy population lives longer and contributes to the development of the nation. It therefore goes to say [7] healthy is wealthy. Hence, developing countries like Zambia have to understand the challenges that exist in providing health care and find ways of overcoming them. This is will contribute significantly to the building of wealthy in these countries.

Information Communication Technologies have been seen to drive business growth globally [8] [9], this is evidenced by the growth of global spending in ICT [10] which is forecasted at $\$ 4.8$ Trillion by the end of 2018. If the business community[11] have benefited from the growth in the ICT sector, it is reasonable that healthy sector can make positive strides as well once ICTs have been put to use.
Studies [12] have shown that the use of ICT in the health sector is capable of increasing efficiency, reducing errors, supporting more team-based care, improving integration of best practice into routine care, enabling consumers to engage more actively in their care, and producing more efficient services through changes in professional roles and responsibilities. The ICT infrastructure [9] required to revolutionaries the business processes in a particular health sector are cheaper to acquire if the cost is compared to the benefits which would accrue.

Information and Communication Technology (ICT) [13] has revolutionizing our lives, our ways to interact with each other, and day-to-day life and work. Its application in health is described broadly as eHealth, which includes telemedicine, electronic medical records, electronic health records and health information systems with decision support, mobile health and eLearning tools. eHealth has shown potential in facilitating a better health care delivery system, leading to better health and universal health coverage. It creates access, enhances quality, improves primary health care interventions and can act as a solution for situations where human resources for health are scarce.

1) Implementation of records systems in hospitals: Many countries [14] are strategically pushing the agenda of implementing EHR through incentives. This because in most of the developed countries particularly in the USA, a lack of adoption of Electronic Health Record is interpreted as a deviation from standard of care. The developed countries have obvious reasons for pushing the agenda of EHR implementation. This because of benefits, which come with this implementation. In addition, if these developed countries discovered the advantage is it just means that developing countries can also benefit from the advantage.

EHR bring about great potential benefits and a high likelihood of outcome. Among them are:

a) The reduction of costs [15] achieved through the reduction in duplication of services and the reduction in the number of personnel through computerization of manual services and automation of coding.

b) Two [16] EHRs improve quality of care due to diminished medical errors by providing healthcare workers with decision support systems. They also promote evidencebased medicine[17] by providing access to unprecedented amounts of clinical data for research that can increase the level of knowledge of effective medical practices.

c) EHRs [14] improve the efficiency and effectiveness with which patient care services are delivered by clinicians. They allow for simultaneous remote access to patient data[18], legibility of records, safer data storage, patient data confidentiality, flexible data layouts, and continuous data processing.

d) EHRs are more reliable due to the presence of a good backup system for disaster recovery.

e) Patient satisfaction is enhanced through the smooth handling of referrals, reduction of the need for multiple tests, 
ease in accessing results and detection of serious health threats that may be life threatening [19].

In view of the aforementioned, benefits of ICTs and particularly EHRs, it is imperative to look at the use of manual records in health care management focusing on the University Teaching Hospital Lusaka.

2) The university teaching hospital and electronic health records: The University Teaching Hospital (UTH) is an integral national referral hospital made up of eight departments. The Department of Surgery has been an integral part of The University Teaching Hospital since the time it was established, by then called Lusaka Central Hospital. It is currently the largest Department with the most diverse specialized units such as; General surgery, Orthopedic and Trauma, Ophthalmology, Urology, Pediatric Surgery, Otorhinolaryngology (ENT), Cardiac, Laparoscopy, Neurosurgery, Maxillofacial, Infrastructure and patient care;

The department has casualty unit, which are entry point for most surgical patients. It also functions as emergency and disaster management unit. They are later channeled to either surgical admission wards for those who need urgent attention or the various specialized clinics appropriately [20].

At present, there are two major systems, which are used for patient's records, and for statistical information and these are Smartcare and DHMIS.

Smartcare [21] is an Electronic Health Record (EHR) System used for management of client health records, generation of reports and in auxiliary services such as pharmacy, labs, logistics and user and provider management. Smartcare is generally considered as being made up of 3 subsystems which are: the trained and certified users, the software system and computers and other physical infrastructure that supports use of the system [22]. The concept behind this system was to enable HIV positive patient access their drugs from any health care facility. Hence, it cannot handle the challenges of a Department like Surgery

The rationale for DHMIS has been that the availability of operational, effective and efficient health management information systems is an essential component of the required district management capacity. The logic is that effective and efficient HMIS will provide district health managers with the information required to make effective strategic decisions that support district performance and sustainability in these decentralized health systems [23]. This system is mainly focused on the management information part. It has been in use at the University Teaching Hospital as well as in many of the Government Hospital through Zambia. The system is an Open source and many countries of the World are using it [24]. Its main use is for statistical data for manager to help them make decision.

These two systems cannot adequately solve the problems associated with the surgery department at the University Teaching Hospital in Lusaka.

\section{Problem Statement}

The surgery department despite being the largest of the eight (8) department of the University Teaching of Zambia has not taken advantage of benefits which arise from the adoption of Electronic Health Records. The diversity of clinicians who participate in surgical procedure also require not just EHR adoption, but a semantically standardized one. Sematic Standardization involves the application of coding system Snomed CT to help curb possibilities of ambiguities which can lead to misunderstanding resulting mishandling of patients.

UTH Surgery being the national referral center has a high number of cases thereby causing a big challenge in the scheduling of patients in the limited number of operating rooms. Despite the limited number of operating rooms availability, the major problem also arises due to the lack of preoperative information due to the absence of Standardized EHR.

The efficient scheduling of surgical procedures in the operating room suites is dependent on maximizing the use of each suite, while accommodating the surgeons' requests for a specific date, time, routine supplies, and any special instruments and/or supplies required for the procedure. Tracking surgeons' preferences and average times for procedures is cumbersome and often inaccurate without the benefit of computerization, especially in an environment having many surgeons and a high volume of procedures.

Without easily accessible and accurate historical information for average times, delays in the schedule will impact negatively on customer service and drive costs upward. If information is difficult to attain, cost analysis per procedure or economic credentialing for individual surgeons proves to be almost impossible to attain.

The operating room impacts the clinical, financial, and administrative practices of many other departments throughout the hospital. From the time the procedure is scheduled, until the patient is discharged, accurate information must be communicated to ensure that efficient and effective patient care is provided as well as the proper allocation of resources [18].

\section{E. Objectives}

The goal of this study is to review the systems which in use at the University Teaching Hospital of Lusaka's surgery department, understand the challenges and suggest solutions by proposing an EHR model.

\section{Methodology}

In the quest to establish the Patient Record System being used at the University Teaching Hospital in Lusaka, a descriptive quantitative analysis was used. This supported further by formal and informal interviews with stakeholder. Record inspection was done by going through all the books and files involved in the patient care management process from the time the patient arrives to the time of discharge.

Convenient sampling was used due to time and the nonaccessibility of the target population. The population is made of clinicians who are very busy. A total of 48 questionnaires 
were administered and only 40 were successfully answered. This represented a response rate of $83 \%$.

The questionnaire data were entered into a statistical package called SPSS version 20 and descriptive statistics showing frequency and percentage were obtained.

After analysing the result of the baseline, record inspection and focus group discussion with the members of staff of the Department of Surgery University teaching Hospital was done.

This was followed by a review from literature of Surgical Operating Room (OR) patient scheduling methods. From the studied methods one was picked and as the solution to be implemented in the system.

The important design that was carried out was the application of the sematic standardisation coding system called Snomed CT. For the international version of Snomed, CT was adopted for easy access and the design of incorporating it into the system was developed.

\section{FINDINGS}

The findings are presented here beginning with descriptive from the questionnaire, followed by records inspection, the patient flow chart and finally the Excel Database used to enter patient data.

Table 1 is demographic descriptive of the respondents covering gender, age group, highest level of education, job title and length of time working in the department.

Out of a total of 40 respondents, 20(50\%) were female and $20(50 \%)$ were male. $4(10 \%)$ out of a total of 40 reported that they were below the age of $29,9(22.5 \%)$ out of 40 reported that they were aged between $30-39,16(40 \%)$ out of 40 were between 40-49 years, 11(27.5\%) out of 40 were 50 years and above. In terms of highest level of education, $5(12.5 \%)$ were certificate holders, $13(32.5 \%)$ were diploma holders, $14(35 \%)$ were degree holders and $8(20 \%)$ were holders of post graduate qualifications.

For the variable Job title, 5(12.5\%) were nurses, $9(22.5 \%)$ were doctors, $20(50 \%)$ were surgeons and $5(12.5 \%)$ were anesthetist. In terms of the numbers of years the respondents have been working with the department of surgery, $3(7.5 \%)$ reported to have been in the department for less than a year, $13(32.5 \%)$ reported to have been in the department between 15years, $13(32.5 \%)$ had been with the department 6-10 years and $11(27.5 \%)$ have spent more than 10 years at the department.

The question of infrastructure is very important was important especially the existence of a personal computer. Table 2 shows that $29(72.5 \%)$ out of 40 reported that they had a computer in their department or office, and 11(27.5\%) out of 40 reported that they did not have a computer.

Table 3 shows that $1(2.5 \%)$ reported that the department had fully implemented electronic record system, 24(60\%) reported that the department was using both paper based and electronic health record system, and $15(37.5 \%)$ reported that they did not have an electronic record system.
TABLE I. DEMOGRAPHIC DATA

\begin{tabular}{|c|c|c|}
\hline GENDER & FREQ & PERC \\
\hline male & 20 & 50.0 \\
\hline female & 20 & 50.0 \\
\hline Total & 40 & 100.0 \\
\hline \multicolumn{3}{|l|}{ AGE GROUP } \\
\hline Under 29 years & 4 & 10.0 \\
\hline 30-39 years & 9 & 22.5 \\
\hline 40-49 years & 16 & 40.0 \\
\hline 50 years or over & 11 & 27.5 \\
\hline Total & 40 & 100.0 \\
\hline
\end{tabular}

HIGHEST LEVEL OF EDUCATION

\begin{tabular}{|l|c|c|}
\hline Certificate & 5 & 12.5 \\
\hline Diploma & 13 & 32.5 \\
\hline Graduate & 14 & 35.0 \\
\hline Post Graduate & 8 & 20.0 \\
\hline Total & 40 & 100.0 \\
\hline
\end{tabular}

JOB TITLE

\begin{tabular}{|l|c|c|} 
Nurse & 5 & 12.5 \\
\hline Doctor & 9 & 22.5 \\
\hline Surgeon & 20 & 50.0 \\
\hline anesthetist & 5 & 12.5 \\
\hline Record Clerk & 1 & 2.5 \\
\hline Total & 40 & 100.0 \\
\hline
\end{tabular}

FOR HOW LONG HAVE YOU BEEN WORKING IN THIS FACILITY

\begin{tabular}{|l|l|l|}
\hline Less than 1 year & 3 & 7.5 \\
\hline $1-5$ years & 13 & 32.5 \\
\hline $6-10$ years & 13 & 32.5 \\
\hline More than 10 years & 11 & 27.5 \\
\hline Total & 40 & 100.0 \\
\hline
\end{tabular}

TABLE II. EXISTENCE OF COMPUTER IN THE DEPARTMENT OR SECTION

\begin{tabular}{|c|c|c|}
\hline $\begin{array}{l}\text { IS THERE A } \\
\text { COMPUTER(S) IN YOUR } \\
\text { DEPARTMENT? }\end{array}$ & FREQUENCY & PERCENT \\
\hline yes & 29 & 72.5 \\
\hline no & 11 & 27.5 \\
\hline Total & 40 & 100.0 \\
\hline
\end{tabular}


TABLE III. LEVEL OF ELECTRONIC RECORDS IMPLEMENTATION

\begin{tabular}{|c|c|c|}
\hline $\begin{array}{l}\text { CHOOSE WHAT BEST DESCRIBES THE LEVEL OF } \\
\text { ELECTRONIC MEDICAL RECORD SYSTEM IN YOUR } \\
\text { DEPARTMENT? }\end{array}$ & FREQUENCY & PERCENT \\
\hline Management of health records in this department is electronic. & 1 & 2.5 \\
\hline $\begin{array}{l}\text { Management of health records in this department is hybrid } \\
\text { (partially electronic and partially paper-based.) }\end{array}$ & 24 & 60.0 \\
\hline We do not have electronic medical records in this department. & 15 & 37.5 \\
\hline Total & 40 & 100.0 \\
\hline
\end{tabular}

From Table 4, the response using a Likert scale (1 strongly disagree, 2 disagree, 3 uncertain, 4 agree, 5 strongly agree) to the statement: the scheduling of patients to be operated on is known in advance, except for emergency cases were, $3(7.5 \%)$ out of 40 disagree, $16(40 \%)$ were uncertain, 17(42.5\%) agree, $4(10 \%)$ strongly agree. Combined total of those whose were uncertain and those who disagreed, we have almost $40.75 \%$ of respondents who disagree or are not sure about every important statement.

Using the Likert scale as explained above, the respondents to the statement; Information regarding a particular patient before surgery is readily available during operation procedures as follows: $2(5 \%)$ out of 40 strongly disagreed, $6(15 \%)$ out of 40 disagreed, $15(37.5 \%)$ were uncertain, $14(35 \%)$ out of 40 agreed and $3(7.5 \%)$ strongly agreed.

Using the Likert scale as explained above, the respondents to the statement; all supplies necessary for operation procedure are known in advance via existing system and are made available before commencement of operation procedure as follows: $1(2.5 \%)$ out of 40 strongly disagreed, $7(17.5 \%)$ out of 40 disagreed, $14(35 \%)$ were uncertain, $15(37.5 \%)$ out of 40 agreed and $3(7.5 \%)$ strongly agreed.

The first part of Table 5 shows ratings by respondents on the privacy and security of patient's medical data. $7(17.5 \%)$ disagreed, 22(55\%) were uncertain, 11(27.5) agreed. The second part of Table 5 shows ratings by respondents regarding easiness of reports generation under the current system. $3(7.5 \%)$ disagreed, 26(65\%) were uncertain, 10(25\%) agreed, and $1(2.5 \%)$ strongly agreed. The third part of Table 5 shows the respondents rating of their level of satisfaction with the current system being use. $1(2.5 \%)$ were very satisfied, $20(50 \%)$ were dissatisfied, 17(42.5\%) were uncertain with their level of satisfaction, 2(5\%) were satisfied.

TABLE IV. OPERATING ROOM AND PATIENT SCHEDULING

\begin{tabular}{|c|c|c|c|}
\hline \multicolumn{2}{|c|}{$\begin{array}{l}\text { The Schedule of patients to be operated on is known in advance, except } \\
\text { for emergency cases }\end{array}$} & \multirow{2}{*}{$\begin{array}{l}\text { Frequency } \\
3 \\
\end{array}$} & \multirow{2}{*}{$\begin{array}{l}\text { Percent } \\
7.5 \\
\end{array}$} \\
\hline & disagree & & \\
\hline & uncertain & 16 & 40.0 \\
\hline & agree & 17 & 42.5 \\
\hline & strongly agree & 4 & 10.0 \\
\hline & Total & 40 & 100.0 \\
\hline \multicolumn{4}{|c|}{ Information regarding a particular patient before surgery is readily available during operation procedures } \\
\hline & strongly disagree & 2 & 5.0 \\
\hline & disagree & 6 & 15.0 \\
\hline & uncertain & 15 & 37.5 \\
\hline & agree & 14 & 35.0 \\
\hline & strongly agree & 3 & 7.5 \\
\hline & Total & 40 & 100.0 \\
\hline \multicolumn{4}{|c|}{$\begin{array}{l}\text { All supplies necessary for operation procedure are known in advance via existing system and are made available before commencement of operatio } \\
\text { procedure }\end{array}$} \\
\hline \multirow{6}{*}{ Valid } & strongly disagree & 1 & 2.5 \\
\hline & disagree & 7 & 17.5 \\
\hline & uncertain & 14 & 35.0 \\
\hline & agree & 15 & 37.5 \\
\hline & strongly agree & 3 & 7.5 \\
\hline & Total & 40 & 100.0 \\
\hline
\end{tabular}


TABLE V. PATIENT SCHEDULING, REPORT GENERATION, LEVEl OF SATISFACTION

\begin{tabular}{|c|c|c|}
\hline Rating in terms of privacy and security of patient's medical data & Frequency & Percent \\
\hline disagree & 7 & 17.5 \\
\hline uncertain & 22 & 55.0 \\
\hline agree & 11 & 27.5 \\
\hline Total & 40 & 100.0 \\
\hline \multicolumn{3}{|l|}{ Rating of report generation with the current system } \\
\hline disagree & 3 & 7.5 \\
\hline uncertain & 26 & 65.0 \\
\hline agree & 10 & 25.0 \\
\hline strongly agree & 1 & 2.5 \\
\hline Total & 40 & 100.0 \\
\hline \multicolumn{3}{|l|}{ Rating of Level of Satisfaction with the current system } \\
\hline very dissatisfied & 1 & 2.5 \\
\hline dissatisfied & 20 & 50.0 \\
\hline uncertain & 17 & 42.5 \\
\hline satisfied & 2 & 5.0 \\
\hline Total & 40 & 100.0 \\
\hline
\end{tabular}

\section{A. Findings from Record Inspection}

Despite, what the quantitative results from the questionnaire have revealed, the picture on the ground was better painted by the actual physical inspection of the systems being used by the UTH Surgery Department. Permission was obtained to capture the books which were used to register patients when they arrive at the hospital, admission registered, ward round progress report, operation room scheduling book, shift book report. Fig. 1 shows some of the books that are being used for managing patient records.

The patient traffic chart, shown in Fig. 2, indicates two possible points of entry into the Hospital depending on the condition of the patient. Post trauma patient or Mass Casualty event victims will enter through the emergency room, if they have relatives with them, registration is done on their behalf, the nurse will collect vitals and at the same time screening by the medical officers at casualty is done.

The other entry is for cold cases or non-emergency cases. These start off by first registering their details with the clerk at the reception, from here they proceed to the casualty nurse for collection of the vitals and once they finish here, the proceed to the screening rooms (casualty medical officers.

After the patient has been screened, they can be taken for further imaging (xray, ultrasonography, CT), then proceed to the surgical ward which can either be male or female ward depending on their gender. Or after a patient has been screened, they can proceed to either the male or female surgical ward depending on their gender. The next place they go to is Phase $\mathrm{V}$ Operating Theatre (Emergency OR). From this theatre, a patient can be taken to C-block wards or Intensive Care Unit (ICU) or G-block wards for recovery until discharge. If the patient is taken to ICU, it means they mean need to go to Phase III Operating room. The chart below shows the patient flow chart.

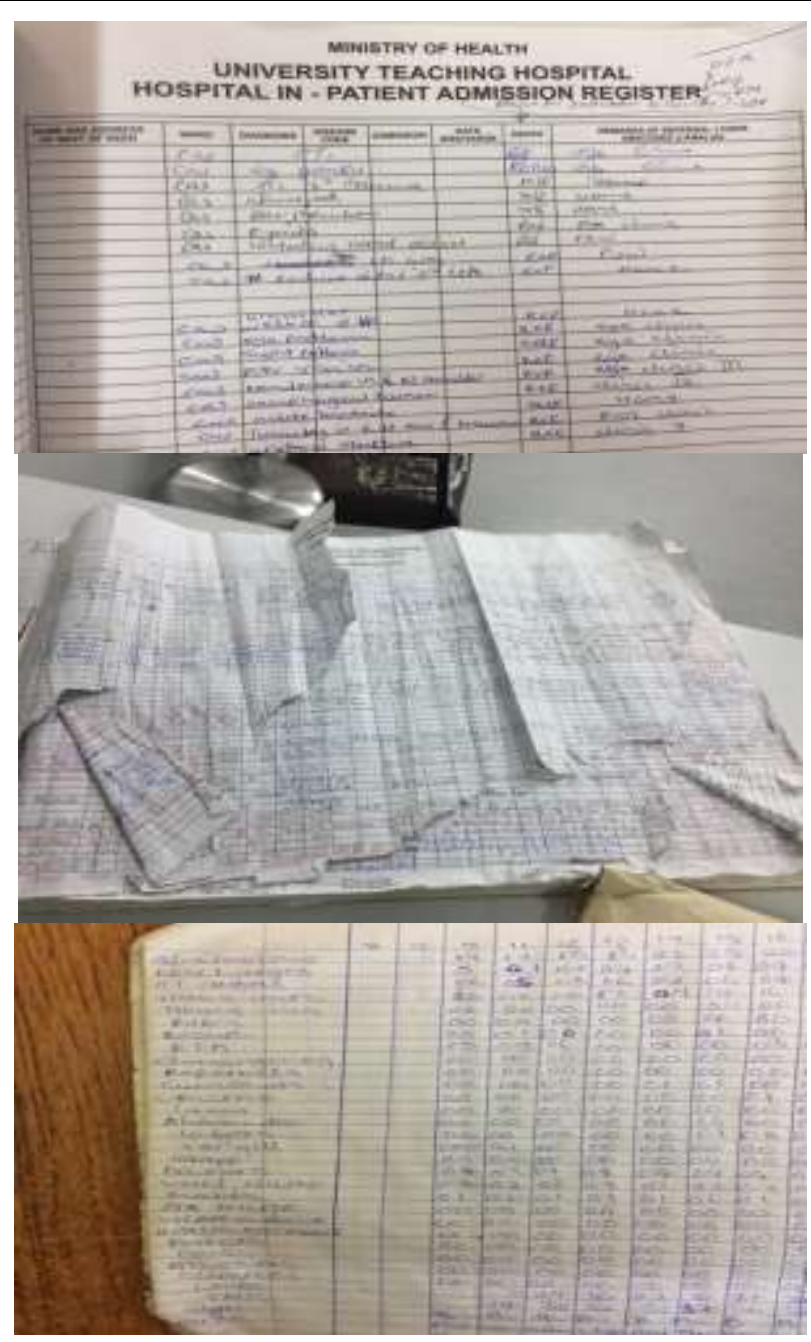

Fig. 1. Pictures of Manual Records in use. 


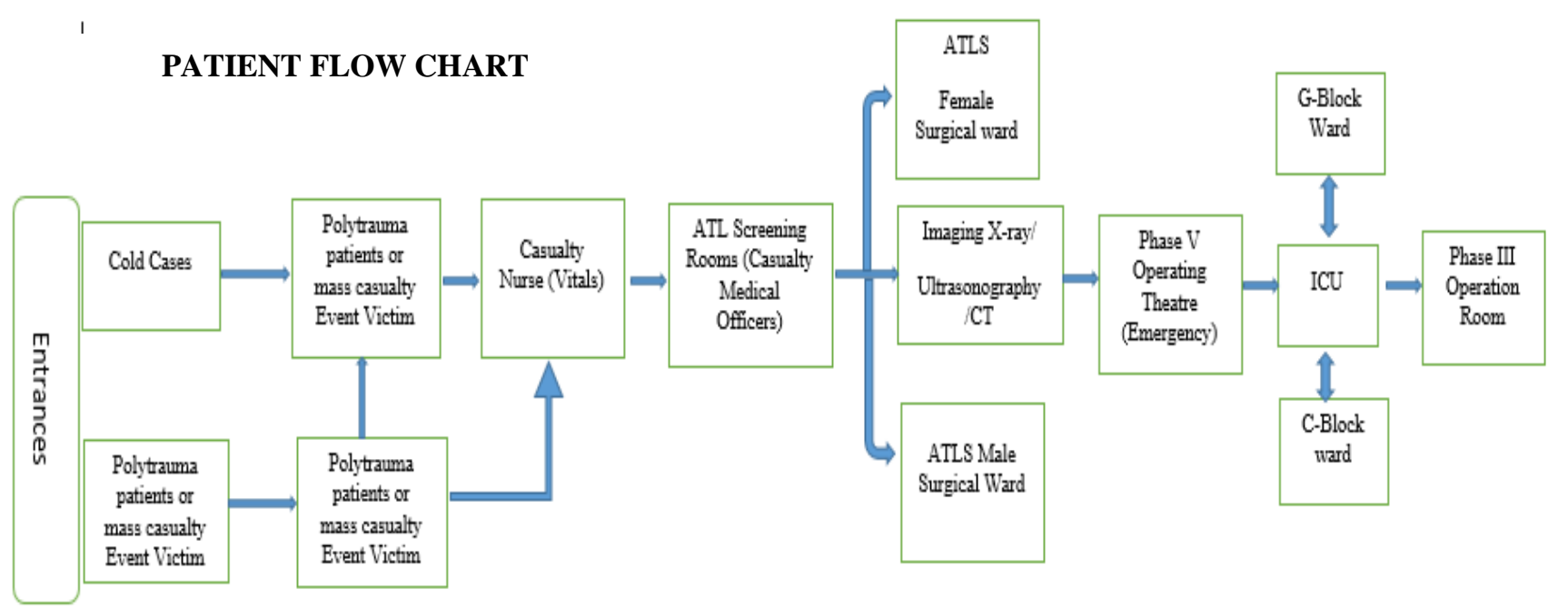

Fig. 2. Patient Flow Chart.

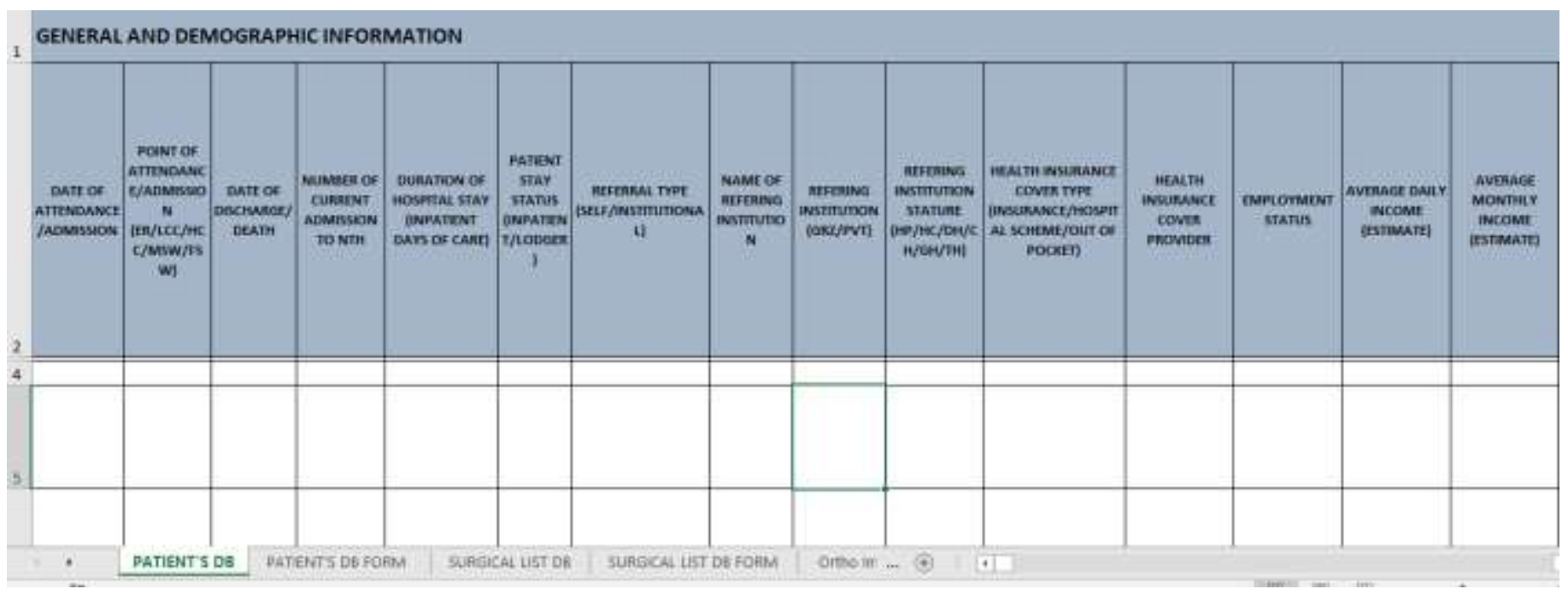

Fig. 3. Sample Ms Excel Information System.

\section{B. Microsoft Excel Database}

In order to take advantage of the computers which currently exist in the department, the person who are sophisticated computer users have developed a database to help register patient details, schedule patients for operations, plan operation supplies and record outcome. Fig. 3 shows the sample screen shoots capture for the MS Excel Database or Record System.

\section{Solution Design}

After establishing the need on the ground through the baseline survey conducted. There was need to design a system that will fully respond to the challenges being faced. The two main areas design which this paper focusses on is the scheduling of patients and block scheduling system was chosen [25]. The design also took into consideration the application of Standardised Nomenclature of Medical Terms Clinical Terms (SNOMED CT). For the purpose of eliminating sematic ambiguities, Snomed CT is proposed. Snomed CT will be integrated within the system by enabling the user of the EHR system to open the International Snomed CT browser [26] with the application. In addition, an offline terminology application will be installed together with the system on the user machine. The user will there have two options, online browser which actually require internet accessibility or the offline system called CliniClue. When Snomed browser is accessed, the user will be able to find the concept Id for the particular diagnosis or prescription. This Id will be entered along aside the description but in a different text box. This diagnosis or prescription, when it is viewed, will enable the user to authentic the writing by looking up the Id provided.

The proposed solution is designed with interoperability in mind. The architecture of the proposed solution is as shown in Fig. 4. Electronic Health Record System interoperable by design [27]. HL-7 [28] is the Standard proposed for Application Programming Interface which will enable future systems from other departments and Hospitals to link to the proposed solution.

SNOMED CT provide for the elimination of ambiguities by coding the human body part or disease [29]. 


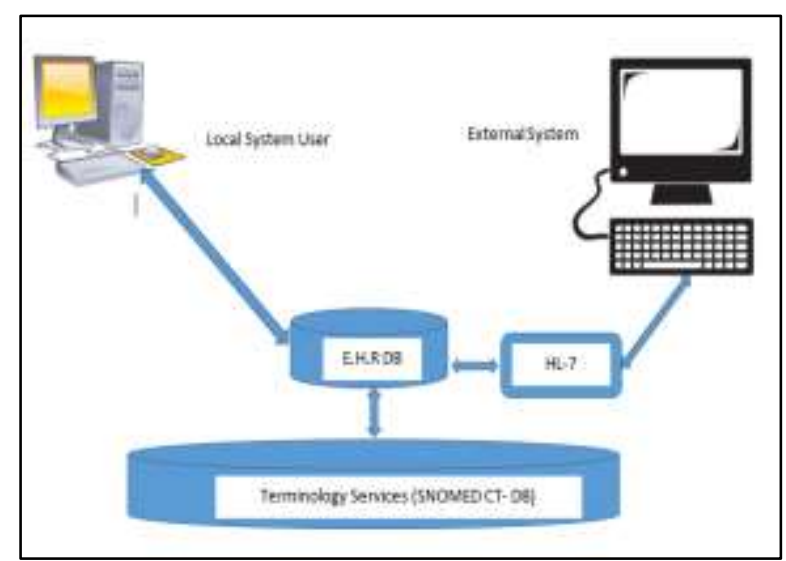

Fig. 4. General System (HER) Architecture.

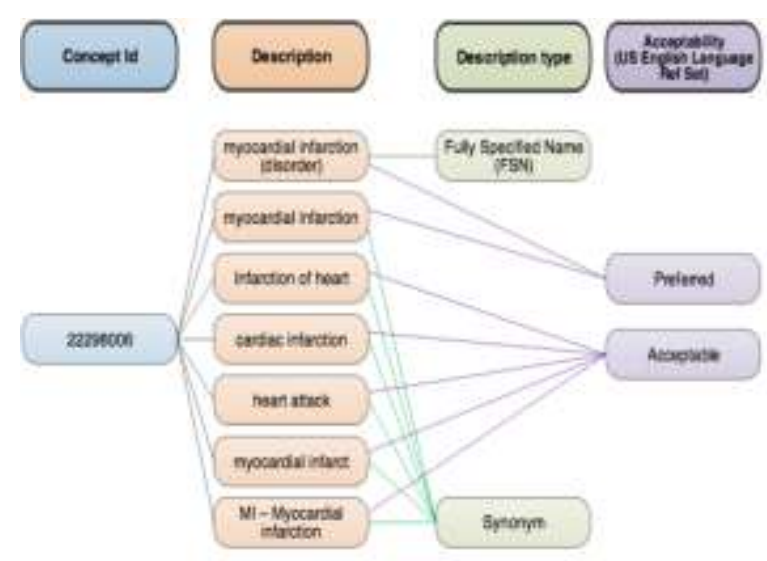

Fig. 5. Snomed CT Description of Concepts.

Fig. 5 shows the four categories in which a medical concept is divided. First, it's given an Identification number, then, the number is mapped to various terms used to describe this concept. This is followed by the description type and accessibility. Ambiguities arise from the many ways in which a particular concept is described. Clinicians can use this description in diagnosis or prescription. The differences in description can result in misunderstanding thereby leading to wrong interpenetration or even wrong prescription. By providing a Concept Id, each clinician will be in a position to interpret the concept in the same manner.

\begin{tabular}{|c|c|c|c|c|}
\hline SNONED CT & English & Frenth & Kinyarwanda & Swahli \\
\hline $27: 737000$ & Aneria & Anemie & Kutura amaraso & $\begin{array}{l}\text { Upurgufu wa } \\
\text { damu }\end{array}$ \\
\hline 196967021 & Asthen & Asthe & Asins & \\
\hline 32272005 & Commsn coild & & & Homa ya nstita \\
\hline 9626008 & Conjunctivits & Conionctivita & Indwrac z'aniso & \\
\hline 80967201 & Oental caries & Carie dectaine & & \\
\hline 62315009 & Darthes & & & Kutars \\
\hline 7520000 & $\begin{array}{l}\text { Fever of uninown } \\
\text { orign }\end{array}$ & Fievre & Unvivo & \\
\hline 25374505 & Gastwontertis & Gasroembith & Kunda no khita & \\
\hline 399221021 & $\begin{array}{l}\text { Geeria bleeting } \\
\text { (vaginal) }\end{array}$ & Himonge gentale & Kuva & \\
\hline 2506402 & Heactache & & & Kusmwa na \\
\hline
\end{tabular}

Fig. 6. Concept ID Mapped to Decryptions in Different Languages.
Fig. 6 is an except table from a study [30] in which an interface was developed to map Snomed CT Concept IDs into description in different languages. This is very helpful especially for an African set up where English is usually a secondary language.

\section{Discussion}

The interviews and round table discussions held with the stakeholder of the department reviewed discontent with the current system. As indicated by the quantitative finding in Table 1, the department has computers and there is local area network (LAN) though it is limited in terms the extent of coverage. This in itself has seem to raise desire for the clinician to automate the business processes. The patient record which are kept in hardcover books are destroyed every ten years. This then robs the hospital and the patients the much needed patient record history which can be used to track hereditary diseases. The data which is destroyed as per record life span necessitated by lack of storage space, it further makes the country lose credible data which can be used for research purposes. There seem be to also a lack of understanding of what an Electronic Health Record System is, some who have indicated that they are using both paper based and Electronic Health Record System are mistakenly referring to the Excel Data base as EHR. It can further be observed that the scheduling of patients, readiness of important information required before surgery is not adequately handled by the current system. This is affirmed by the fact that $50 \%$ are dissatisfied while $42.5 \%$ are not sure or uncertain about it. For a department has important as surgery, the personnel must have great confidence in their tools and systems for better patient care provision. The results have also shown that the patient's records are not very private and secure. The is makes clinicians vulnerable to legal law suits depending on whose hands some patients 'record may be found in. Furthermore, the finding shows that $60 \%$ of the respondents were not certain of the current manual system's ability to give accurate required reports.

The MS Excel Database is very inadequate to provide the department with the type of information that may need.

\section{CONCLUSION}

The University Teaching Hospital Lusaka Department of Surgery as national referral center and does not have an Electronic Health Record system which can assist in patient record registration, keeping track of disease history and assist in the optimal and efficient utilization of resources such as operating room both scheduling, providing preoperative information and post operation follow up.

It is for this resource that it important that the records of the department should be computerized and standardized.

\section{ACKNOWLEDGMENT}

We would like to thank the University Teaching Hospital Department of Surgery for giving us the access to sensitive patient records and allowing us to get their views on the current system. 
We would like to thank in Particular Dr Denise Sakala for the effort in helping to get permission to the entire Department's section for record inspection.

We would like to thank all the lecturers who help shape the study with their positive criticisms.

\section{REFERENCES}

[1] Garets and M. Davis, "Electronic Medical Records vs. Electronic Health Records: Yes, There Is a Difference A HIMSS Analytics TM White Paper Source: HIMSS Analytics Database (derived from the Dorenfest IHDS+ Database TM )," pp. 1-14, 2006.

[2] "What are the advantages of electronic health records? HealthIT.gov." [Online]. Available: https://www.healthit.gov/faq/what-are-advantageselectronic-health-records. [Accessed: 25-Jan-2019].

[3] E. Commission, "EC ACTIVITIES ON SNOMED CT - SEMANTIC INTEROPERABILITY 4th Meeting of the eHealth Network For consultation by the eHealth Network 3 . SNOMED CT in EU."

[4] "Data Analytics with SNOMED CT," pp. 1-73, 2015.

[5] T. Schramme and S. D. Edwards, Handbook of the philosophy of medicine.

[6] N. Sartorius, "The meanings of health and its promotion.," Croat. Med. J., vol. 47, no. 4, pp. 662-4, Aug. 2006.

[7] Thomas Muyumba, Jackson Phiri, "A Web based Inventory Control System using Cloud Architecture and Barcode Technology for Zambia Air Force". International Journal of Advanced Computer Science and Applications,8 (11), p. 132-142, 2017.

[8] Annie Mpolokoso, Jackson Phiri, "Managing customary land conflicts and demarcations using mobile applications tools: a case study of Zambia" International Journal of Wireless and Mobile Computing, Volume 15 Number 4, p. 323 - 334

[9] Johnson I Agbinya, Nazia Mastali, Rumana Islam, Jackson Phiri,"Design and Implementation of Multimodal Digital Identify Management System Using Fingerprint Matching and Face Recognition" in Int. Conf. on broadband communication and biomedical applications, Melbourne, Australia, pp. 273, 2011.

[10] "2018 IT (Information Technology) Industry Trends Analysis | CompTIA." [Online]. Available: https://www.comptia.org/resources/itindustry-trends-analysis. [Accessed: 02-Sep-2018]

[11] Kingford Mutinta Haakalaki, Jackson Phiri, Monica Kalumbilo Kabemba, "A Model for an Electronic Health Information Management System with Structural Interoperability in Heterogeneous Environments for continued Health Care", Zambia ICT Journal, Volume 2, Number 2, p. $28-35,2018$.

[12] J. I. Westbrook et al., "Use of information and communication technologies to support effective work practice innovation in the health sector: a multi-site study,” BMC Health Serv. Res., vol. 9, no. 1, p. 201, Dec. 2009.

[13] P.-G. Svensson, "eHealth Applications in Health Care Management.," eHealth Int., vol. 1, no. 1, p. 5, Sep. 2002.

[14] C. P. Stone, "A Glimpse at EHR Implementation Around the World: The Lessons the US Can Learn," 2014.

[15] A. Lee Gonzalez Fanfalone, "Benefits and Costs of the Infrastructure Targets for the Post-2015 Development Agenda," 2015.
[16] C. Castaneda et al., "Clinical decision support systems for improving diagnostic accuracy and achieving precision medicine.," J. Clin. Bioinforma., vol. 5, p. 4, 2015.

[17] E. V Murphy, "Clinical decision support: effectiveness in improving quality processes and clinical outcomes and factors that may influence success.," Yale J. Biol. Med., vol. 87, no. 2, pp. 187-97, Jun. 2014.

[18] S. A. Bantom and R. De La Harpe, "ACCESSIBILITY TO PATIENTS' OWN HEALTH INFORMATION: A CASE IN RURAL EASTERN CAPE, SOUTH AFRICA," 2016.

[19] S. Bah, H. Alharthi, A. A. El Mahalli, A. Jabali, M. Al-Qahtani, and N. Al-kahtani, "Annual survey on the level and extent of usage of electronic health records in government-related hospitals in Eastern Province, Saudi Arabia.," Perspect. Heal. Inf. Manag., vol. 8, no. Fall, p. 1b, 2011.

[20] University Teaching Hospital, "SURGERY | The University Teaching Hospital," $2015 . \quad$ [Online]. Available: http://www.uth.gov.zm/?page_id=663. [Accessed: 02-Sep-2018].

[21] "Bolstering Use of Smartcare Electronic Health Records System | UNDP in Zambia." [Online]. Available: http://www.zm.undp.org/content/zambia/en/home/presscenter/articles/20 14/02/03/bolstering-use-of-smartcare-electronic-health-recordssystem.html. [Accessed: 30-Oct-2018].

[22] "Zambia Leads the Way in SmartCare Electronic Health Records System, A Benefit to Both Providers and Patients | Jhpiego." [Online]. Available: https://www.jhpiego.org/success-story/zambia-leads-theway-in-smartcare-electronic-health-records-system-a-benefit-to-bothproviders-and-patients/. [Accessed: 30-Oct-2018].

[23] R. Dehnavieh et al., "The District Health Information System (DHIS2): A literature review and meta-synthesis of its strengths and operational challenges based on the experiences of 11 countries," Heal. Inf. Manag. J., p. 183335831877771 , Jun. 2018.

[24] "DHIS2 - Transforming Health IT Standards in the Developing World (Part 2) | Open Health News." [Online]. Available: http://www.openhealthnews.com/articles/2017/dhis2-transforminghealth-it-standards-developing-world-part-2. [Accessed: 26-Oct-2018].

[25] E. Erdem, J. Szmerekovsky, X. Qu, and R. Boyer, "Optimization Models for Scheduling and Rescheduling Elective Surgery Patients under the Constraint of Downstream Units Dr. Canan Bilen-Green Date Department Chair."

[26] "SNOMED CT-Clinical finding (finding)." [Online]. Available: https://browser.ihtsdotools.org/?perspective=full\&conceptId $1=4046840$ 03\&edition=enedition\&release $=\mathrm{v} 20180731$ \&server=https://browser.ihtsdotools.org/api/ v1/snomed\&langRefset=900000000000509007. [Accessed: 13-Dec2018].

[27] A. S. Apostol, C. Catu, and C. Vernic, "Electronical Health Record's Systems. Interoperability,” An. Ser. Inform., vol. I, no. 1, p. 14, 2009.

[28] E. S. Torres, "Conception of a SNOMED CT and HL7 V3 standard: domain analysis model of preoperative anesthesia assessment project," no. May, 2010.

[29] "HealthCare Tagging of Verbal Autopsies using SNOMED-CT Rebecca West MSc Computing \& Management Session 2009 / 2010,” 2010.

[30] "Kanter- Interface terminologies for Africa," no. December, 2013. 